\title{
大麦种质资源成株期抗旱性鉴定及抗旱指标篮选
}

徐银萍 潘永东* 刘强德 姚元虎 贾延春 任诚 火克仓陈文庆
赵

甘肃省农业科学院经济作物与啤酒原料研究所, 甘肃兰州 730070

摘 要: 干旱是影响大麦生产的主要因素之一。在鉴定大麦种质资源成株期抗旱性的基础上, 篮选抗旱指标, 可为培 育抗旱品种提供依据。本研究在 2016 和 2017 年在大麦生长主要需水期平均降雨量不足 $40 \mathrm{~mm}$ 的甘肃省武威市进行 田间试验, 以 30 份大麦种质资源为研究对象, 设置正常灌水和干旱胁迫处理, 测定大麦株高、穗长、分櫵数、单株 粒数、单株粒重、穗粒数、千粒重和产量, 采用抗旱性度量值 $(D)$ 、综合抗旱系数 $(C D C)$ 、加权抗旱系数(WDC)、相 关分析、频次分析、主成分分析、灰色关联度分析、隶属函数分析、聚类分析和逐步回归分析相结合的办法, 对其 进行抗旱性鉴定及抗旱指标的篮选。干旱胁迫对测定的各指标均有极显著影响。频次分析表明, 各指标对干旱胁迫 反应的敏感程度依次为产量、株高、单株粒重、穗长、单株粒数、分暞数、穗粒数和千粒重。相关分析表明, 产量 与株高、穗长、分菜数、单株粒数和单株粒重呈极显著正相关，与穗粒数呈显著正相关、与千粒重呈不显著正相关。 主成分分析表明, 5 个主成分可以代表大麦抗旱性 $86.39 \%$ 的原始数据信息量。基于 D 值、CDC 值和 WDC 值的大麦 种质资源抗旱性排序基本一致。灰色关联度分析表明, 各指标单项抗旱系数值与 D 值间的关联度依次为产量、单株 粒重、单株粒数、穗长、株高、分藍、穗粒数和千粒重, 各指标 DC 值与 WDC 值间的关联大小依次为单株粒重、产 量、单株粒数、分藍、穗长、穗粒数、株高和千粒重。根据 D 值进行聚类分析, 将供试大麦种质资源依据抗旱性从 强到弱分为 5 个抗旱等级, 其中 1 级 5 份、2 级 1 份、3 级 11 份、4 级 10 份、5 级 3 份。除分薛和千粒重外, 其余指 标的隶属函数值、 CDC 值、 $D$ 值和 WDC 值均随着抗旱级别的升高而增大。回归分析表明, 5 个测定指标均与 D 值密 切相关。干旱胁迫对大麦种质资源成株期各指标均有极显著影响。确定了 $D$ 值为适宜的抗旱鉴定指标。篮选出成株 期抗旱性强的大麦种质资源甘啤 7 号、Z06-278-9、MERIT、NEVADA 和西藏 25, 可为大麦抗旱育种、抗旱机制以 及干旱调控缓解机制的研究提供技术支持。穗长、单株粒数、单株粒重、穗粒数、产量可作为大麦种质资源成株期

简单、直观的抗旱评价指标。

关键词: 大麦(Hordeum vulgare L.); 成株期; 抗旱性; 抗旱指标

\section{Drought resistance identification and drought resistance indexes screening of barley resources at mature period}

XU Yin-Ping, PAN Yong-Dong", LIU Qiang-De, YAO Yuan-Hu, JIA Yan-Chun, REN Cheng, HUO Ke-Cang, CHEN Wen-Qing, ZHAO Feng, BAO Qi-Jun, and ZHANG Hua-Yu

Institute of Industrial Crops and Malting Barley, Gansu Academy of Agricultural Sciences, Lanzhou 730070, Gansu, China

\footnotetext{
本研究由甘肃省国际科技合作项目 (17YF1WA156), 甘肃省农业科学院农业科技创新专项科技支撑计划项目 (2018GAAS02), 甘肃省农 业科学院科技自主创新专项现代生物育种项目 (2019GAAS08), 甘肃省农业科学院科研条件建设及成果转化中青年基金项目 (2017GAAS74)和国家现代农业产业技术体系建设专项(CARS-05)资助。

This study was supported by Gansu International Science and Technology Cooperation Project of China(17YF1WA156), Gansu Academy of Agricultural Sciences Agricultural Science and Technology Support Program of China (2018GAAS02), Gansu Academy of Agricultural Sciences Modern Biological Breeding Project of China (2019GAAS08), Gansu Academy of Agricultural Young and Middle-aged Fund Project of China (2017GAAS74), and China Agriculture Research System (CARS-05).

*通信作者(Corresponding author): 潘永东, E-mail: panyongdong1010@163.com

第一作者联系方式: E-mail: xuyinping7810@163.com

Received (收稿日期): 2019-04-17; Accepted (接受日期): 2019-08-09; Published online (网络出版日期): 2019-10-14.

URL: http://kns.cnki.net/kcms/detail/11.1809.S.20191014.1519.011.html
} 


\begin{abstract}
Drought is one of the major factors affecting barley production. Identification of drought resistance of barley resource at maturity stage, could provide and their associating indexes a basis for breeding drought-resistant cultivars. Field experiments were carried out in Wuwei city, Gansu province, in 2016 and 2017, where the average rainfall during the main water requirement period is less than $40 \mathrm{~mm}$. thirty barley resource under measured normal irrigation and drought stress were used to measured plant height, spike length, tiller number, grain number per plant, grain weight per plant, grain number per spike, 1000-grain weight and yield of barley. Drought resistance comprehensive evaluation value ( $D$-value), comprehensive drought resistance coefficient (CDC-value), weight drought resistance coefficient (WDC-value), correlation analysis, frequency analysis, principal component analysis, grey relational analysis, subordinate function analysis, clustering analysis, and stepwise regression analysis were combined to identify the drought resistance and to screen drought resistance indexes of tested resource at mature period. Drought stress had significant effects on all measured indexes. Frequency analysis showed that the sensitivity of each index to drought stress was yield, plant height, grain weight per plant, spike length, grain number per plant, tiller number, grain number per spike and 1000-grain weight. The yield was very significantly and positively correlated with plant height, spike length, tiller number, grain number per plant and grain weight per plant, and significantly and positively correlated with grain number per spike, but not correlated with 1000-grain weight. Principal component analysis showed that five principal components could represent $86.39 \%$ of the original data information of barley drought resistance. The ranks of drought resistance based on the $D$-value, CDC-value, and WDC-value were similar. Grey relational analysis showed that the correlation degree between DC-value of all indexes and $D$-value in turn for yield, grain weight per plant, grain number per plant, spike length, plant height, tiller number, grain number per spike and 1000-grain weight, the correlation degree between DC-value of all indexes and WDC-value in turn for grain weight per plant, yield, grain number per plant, tiller number, spike length, grain number per spike, plant height and1000-grain weight, According to $D$-value clustering analysis, tested barley materials were divided into five drought resistance grades, in which five were in grade 1 , one was in grade 2 , eleven were in grade 3, ten were in grade 4, and three were in grade 5 . Except for tiller number and 1000-grain weight, the subordinate function values, CDC-values, $D$-values, and WDC-values of other indicators were increased with increase of drought resistance grades. Stepwise regression analysis showed that plant height, Spike length, tiller number, grain number per plant, grain weight per plant, grain number per spike, 1000-grain weight and yield were closely related to the $D$-value. Drought stress had significant effects on all indexes of barley resources at mature period. $D$-value was determined as an appropriate index for drought resistance identification. Ganpi 7, Z06-278-9, MERIT, NEVADA, and Xizang 25 were identified as drought resistant barley materials at mature period, which could provide basic materials for the researches on cultivar breeding, drought resistant mechanism, and regulation and alleviation mechanism of drought resistance in barley. The spike length, grain number per plant, grain weight per plant, grain number per spike and yield could be used as the simple and intuitive identification indexes of drought resistance in barley resources at mature period.
\end{abstract}

Keywords: barley (Hordeum vulgare L.); mature period; drought resistance; drought resistance indexes

大麦 (Hordeum vulgare L.) 是世界上最古老的农 作物之一, 距今已有数千年的栽培历史, 是种植最 广的谷类作物。大麦不但具有早熟、耐旱、耐寒和 广适等特点, 而且具有良好的食用、酿造和饲用价 值, 担负着为藏区居民提供粮食, 为麦芽和啤酒工 业提供原料, 为畜牧和水产养殖提供饲料、饲草的 特殊功能。与其他作物相比大麦具有更加广泛的生 态适应性, 被认为是最适宜进行抗旱研究的试验材 料 ${ }^{[1-2]}$, 随着全球水资源匮缺矛盾的加剧, 干旱已成 为我国乃至世界农业生产长期面临的主要制约因 素 ${ }^{[3]}$ 。因此, 鉴定大麦成株期的抗旱性、篮选抗旱指 标, 对大麦抗旱品种选育、抗旱机制及干旱调控机 制的研究均具有重要意义。研究作物抗旱性首要解 决的技术难点就是如何准确鉴定其抗旱性和篮选抗 旱指标, 这需要将不同指标相结合, 对作物各个时 期进行综合评价 ${ }^{[4]}$ 。近年来, 随着不同作物抗旱性研 究的发展, 研究者们为了避免单一指标的片面性和 不稳定性, 先后在谷子 ${ }^{[5-6]}$ 、胡麻 ${ }^{[7-9]} 、 大 \bar{⿱}^{[10-11]} 、$ 油
菜 ${ }^{[12-13]}$ 、棉花 ${ }^{[14]}$ 、高粱 ${ }^{[15-17]}$ 、绿豆 ${ }^{[18-20]}$ 、薏药 ${ }^{[21-22]}$ 等作物抗旱性鉴定及抗旱指标篮选上采用了相关分 析、频次分析、主成分分析、隶属函数分析、聚类 分析、灰色关联度分析和逐步回归分析等相结合的 方法综合评价。目前，对大麦抗旱性鉴定的研究主 要是从大麦萌发期和苗期的形态指标、生理指标、 生长发育指标、生化指标和超微结构形态指标等多 角度进行鉴定、标篮选及种质资源分级评价 ${ }^{[23-33]}$, 但对大麦成株期抗旱性鉴定评价及指标篮选均未涉 及或鲜有报道。本研究设置正常灌水和干旱胁迫 2 个处理, 在大麦生长主要需水期降雨量不足 $40 \mathrm{~mm}$ 的地区进行田间试验，利用综合评价法对30份大麦 种质资源的株高、穗长、有效分㫧数、单株粒数、 单株粒重、穗粒数、千粒重和产量进行鉴定与评价, 从而篮选出成株期抗旱性强的大麦种质资源及易测 定的与大麦抗旱性密切相关的指标, 为开展大麦抗 旱品种选育和抗旱机制及干旱调控缓解机制等方面 的研究提供基础。 


\section{1 材料与方法}

\section{1 供试材料}

大麦种质 30 份，包括美国引进的 10 份、中国 西藏 4 份、中国甘肃甘南州 1 份、中国甘肃省农业 科学院选育品种 7 份、新品系 8 份(表 1 )。

\section{2 试验设计}

2016 年和 2017 年在甘肃省农业科学院武威市
凉州区黄羊镇麦类综合试验站进行田间试验。该区 属于大陆性温带干旱半干旱气候, 位于甘肃省河西 走廊东部，年日照时数为 $2360 ~ 2920 \mathrm{~h}$, 平均海拔 $1766 \mathrm{~m}$, 无霜期 $135 \sim 150 \mathrm{~d}$, 年平均气温 $6.5^{\circ} \mathrm{C}$, 年平 均降雨量 $210 \mathrm{~mm}$, 年蒸发量 $2100 \mathrm{~mm}$ 。试验地土质 为灌漠土, 含有机质 $26.7 \mathrm{~g} \mathrm{~kg}^{-1}$ 、碱解氮 $81.3 \mathrm{mg} \mathrm{kg}^{-1}$ 、 有效磷 $11.2 \mathrm{mg} \mathrm{kg}^{-1}$ 、速效钾 $197 \mathrm{mg} \mathrm{kg}^{-1}, \mathrm{pH} 8.5$ 。

表 130 份大麦种质的来源

Table 1 Origins of 30 barley resources

\begin{tabular}{|c|c|c|}
\hline 编号 & 名称 & 来源 \\
\hline Number & Name & \\
\hline 01 & Z06-278-9 & 美国 USA \\
\hline 02 & Z06-266-10 & 美国 USA \\
\hline 03 & MERIT & 美国 USA \\
\hline 04 & Z06-291-1 & 美国 USA \\
\hline 05 & BARI188 & 美国 USA \\
\hline 06 & BARI160 & 美国 USA \\
\hline 07 & BARI187 & 美国 USA \\
\hline 08 & BARI165 & 美国 USA \\
\hline 09 & 西藏 10 Xizang 10 & 中国西藏 Tibet, China \\
\hline 10 & 西藏 12 Xizang 12 & 中国西藏 Tibet, China \\
\hline 11 & 西藏 23 Xizang 23 & 中国西藏 Tibet, China \\
\hline 12 & 西藏 25 Xizang 25 & 中国西藏 Tibet, China \\
\hline 13 & NEVADA & 美国 USA \\
\hline 14 & 甘啤 6 号 Ganpi 6 & 中国甘肃省农业科学院 Gansu Academy of Agricultural Sciences, China \\
\hline 15 & 甘饲 1 号 Gansi 1 & 中国甘肃省农业科学院 Gansu Academy of Agricultural Sciences, China \\
\hline 16 & 0420-7 (甘啤 4 号杂交后代) Derived from Ganpi 4 & 中国甘肃省农业科学院 Gansu Academy of Agricultural Sciences, China \\
\hline 17 & 0521-6 (甘啤 7 号杂交后代) Derived from Ganpi 7 & 中国甘肃省农业科学院 Gansu Academy of Agricultural Sciences, China \\
\hline 18 & 2153122 (甘啤 7 号杂交后代) Derived from Ganpi 7 & 中国甘肃省农业科学院 Gansu Academy of Agricultural Sciences, China \\
\hline 19 & 0821-2 (MERIT 杂交后代) Derived from MERIT & 中国甘肃省农业科学院 Gansu Academy of Agricultural Sciences, China \\
\hline 20 & 0835-3 (MERIT 杂交后代) Derived from MERIT & 中国甘肃省农业科学院 Gansu Academy of Agricultural Sciences, China \\
\hline 21 & 0844-1 (MERIT 杂交后代) Derived from MERIT & 中国甘肃省农业科学院 Gansu Academy of Agricultural Sciences, China \\
\hline 22 & 0903-2 (法瓦维特杂交后代) Derived from Favorit & 中国甘肃省农业科学院 Gansu Academy of Agricultural Sciences, China \\
\hline 23 & 中黄 1 号 Zhonghuang 1 & 中国甘肃甘南州 Gannan, Gansu, China \\
\hline 24 & 0902-1 (法瓦维特杂交后代) Derived from Favorit & 中国甘肃省农业科学院 Gansu Academy of Agricultural Sciences, China \\
\hline 25 & 陇青 1 号 Longqing 1 & 中国甘肃省农业科学院 Gansu Academy of Agricultural Sciences, China \\
\hline 26 & 甘啤 4 号 Ganpi 4 & 中国甘肃省农业科学院 Gansu Academy of Agricultural Sciences, China \\
\hline 27 & 甘啤 7 号 Ganpi 7 & 中国甘肃省农业科学院 Gansu Academy of Agricultural Sciences, China \\
\hline 28 & 甘啤 8 号 Ganpi 8 & 中国甘肃省农业科学院 Gansu Academy of Agricultural Sciences, China \\
\hline 29 & 甘啤 9 号 Ganpi 9 & 中国甘肃省农业科学院 Gansu Academy of Agricultural Sciences, China \\
\hline 30 & Aspen & 美国 USA \\
\hline
\end{tabular}

设正常灌水 $(\mathrm{CK})$ 和干旱胁迫 $(\mathrm{T}) 2$ 个处理, 3 次 重复, 采用随机区组排列, 小区面积 $12.5 \mathrm{~m}^{2}(2.5$ $\mathrm{m} \times 5.0 \mathrm{~m}$ ), 行距 $0.25 \mathrm{~m}$, 种植 10 行, 区组间隔 $50 \mathrm{~cm}$, 播种行与区组走向垂直, 试验地四周播种 20 行保护
行，分别于 2016 年 3 月 15 日与 2017 年 3 月 18 日 以手锄开沟撒播, 播种量 $300 \mathrm{~kg} \mathrm{hm}^{-2}$ 。播前施纯氮 纯磷各 $150 \mathrm{~kg} \mathrm{hm}^{-2}$ (分别用含氮 $46 \%$ 的尿素和含 $\mathrm{P}_{2} \mathrm{O}_{5} 46 \%$ 的磷酸二铵), 所有化肥均作为基肥播种前 
一次性施入。对照在大麦拔节期和扬花期每次灌水 $1500 \mathrm{~m}^{3} \mathrm{hm}^{-2}$, 干旱胁迫处理全生育期不灌水完全 依靠自然降水。大麦生育期 2 年平均降水量在 $40 \mathrm{~mm}$ 左右。

\section{3 测定项目与方法}

在成株期收获前 $2 \mathrm{~d}$, 从每小区随机拔取 10 株, 量取株高(plant height, PH)和穗长(spike length, SL), 调查单株分䔉数(tiller number, TN), 人工脱粒后统 计单株粒数 (grain number per plant, GNPP), 待自然 干燥后测定单株粒重 (grain weight per plant, GWPP)、穗粒数 (grain number per spike, GNS)、千粒 重(1000-grain weight, TGW)和小区产量(yield, Y)。

\section{4 数据处理与分析}

采用 Microsoft Excel 2013 整理数据、SPSS 18.0 进行统计分析。以 2016 年和 2017 年数据的平均值

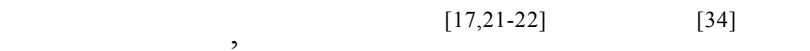

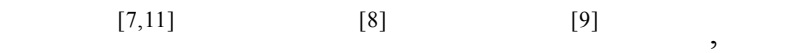
配对处理 $t$ 检验对各指标测定值进行平均数差异显 著性检测。按公式(1)和(2)分别计算单项抗旱系数 (drought resistance coefficient, DC)和综合抗旱系数 (comprehensive drought resistance coefficient, CDC)。 式中 $x_{i}$ 和 $\mathrm{CK}_{i}$ 分别表示干旱胁迫和正常灌水处理的 指标测定值。

$$
\begin{aligned}
& \mathrm{DC}=\frac{T_{i}}{\mathrm{CK}_{i}} \\
& \mathrm{CDC}=\frac{1}{n} \sum_{i=1}^{n} \mathrm{DC}
\end{aligned}
$$

针对各指标 DC 值, 进行简单相关分析、连续变 数次数分布统计分析和主成分分析。按公式(3)、(4) 和(5)分别计算因子权重系数 $\left(\omega_{i}\right)$ 、各基因型各综合指 标的隶属函数值 $\left[\mu\left(x_{i}\right)\right.$ 和抗旱性度量值(drought resistance comprehensive evaluation value, $D)$ 。式中 $P_{i}$ 为第 $i$ 个综合指标贡献率，表示第 $i$ 个指标在所有指 标中的重要程度, $x_{i} 、 x_{i, \max }$ 和 $x_{i, \min }$ 分别表示第 $i$ 个综 合指标及第 $i$ 个综合指的最大值和最小值。

$$
\begin{aligned}
& \omega_{i}=P_{i} \div \sum_{i}^{n} P_{i} \\
& \mu\left(x_{i}\right)=\frac{x_{i}-x_{i, \min }}{x_{i, \max }-x_{i, \min }} \\
& D=\sum_{i=1}^{n}\left[\mu\left(x_{i}\right) \times\left(P_{i} \div \sum_{i}^{n} P_{i}\right)\right]
\end{aligned}
$$

以各指标 $\mathrm{DC}$ 值为比较序列, $D$ 值为参考序列进
行灰色关联度分析，获得各指标 DC 值与 $D$ 值间的 关联度 $\left(\gamma_{D}\right)$, 按公式(6)和(7)分别计算各指标权重系 数 $\left[\omega_{i(\gamma)}\right]$ 和加权抗旱系数 (weight drought resistance coefficient, WDC)。式中 $\gamma_{i}$ 为各指标关联度。

$$
\begin{aligned}
\omega_{i(\gamma)} & =\gamma_{i} \div \sum_{i=1}^{n} \gamma_{i} \\
\mathrm{WDC} & =\sum_{i=1}^{n}\left[\operatorname{DC} \times\left(\gamma_{i} \div \sum_{i=1}^{n} \gamma_{i}\right)\right]
\end{aligned}
$$

以各指标 DC 值为比较序列, WDC 值为参考序 列进行灰色关联度分析, 获得各指标 DC 值与 WDC 值间的关联度 $\left(\gamma_{\mathrm{WDC}}\right)$ 。最后针对供试大麦种质 $D$ 值, 采用欧氏距离和加权配对算术平均法(weighted pair group method average, WPGMA)进行聚类分析, 划 分抗旱级别, 并分别以 $D$ 值、 $\mathrm{CDC}$ 值和 WDC 值为 参考序列，对各指标 DC 值进行逐步回归分析，求取 回归方程。

\section{2 结果与分析}

\section{1 供试种质的代表性及其指标测定值分析}

干旱胁迫对供试种质资源各指标测定值均有 显著影响，处理间和种质材料间的差异均达到显著 水平(表 2 和附表 1)。种质材料间变异系数介于 $0.070 \sim 0.412$, 说明本试验所选用的大麦种质材料 类型丰富, 具有较好的代表性, 干旱胁迫处理效果 好, 所选指标对干旱胁迫反应较敏感。另外, 供试 大麦种质材料各指标在对照和干旱胁迫处理下的 测定值相关系数介于 $0.352 ~ 0.737$, 这进一步说明 各指标对干旱胁迫反应的敏感性存在差异, 直接单 独采用各指标测定值很难鉴定供试大麦种质资源 的抗旱性。

\section{2 单项指标分析}

与正常灌水处理相比，供试大麦种质资源在干 旱胁迫处理后, 各指标均发生不同程度变化(表 3)。 同一个指标各个种质资源的 DC 值存在明显差异, 变异系数介于 $0.066 \sim 0.373$, 但是不同种质资源间 DC 值反映的抗旱性不同，且同一种质资源各指标 的 DC 值差异较大, 说明各指标对干旱胁迫反应的 敏感性不同。

此外, 同一区间各指标 DC 值的分布次数与频 率差异较大 (表 4$) 。 \mathrm{DC}>0.8$ 的株高、穗长、分臨数、 单株粒数、单株粒重、穗粒数、千粒重和产量的分 布频率分别为 $20 \% 、 53 \% 、 67 \% 、 53.5 \% 、 47 \% 、 83 \%$ 、 97\%和 $13.3 \%$, 说明各指标对干旱胁迫反应的敏感 
程度依次为产量、株高、单株粒重、穗长、单株粒指标会由于指标间信息的叠加, 很难准确客观地评 数、分蒏、穗粒数和千粒重。因此，直接采用这些价各种质资源的抗旱性。

表 2 干旱胁迫和正常灌水条件下供试大麦种质各测定指标平均值差异分析

Table 2 Mean values of all indices in tested barley resources under drought stress and normal irrigation

\begin{tabular}{|c|c|c|c|c|c|c|c|c|c|c|c|c|c|c|c|c|}
\hline \multirow{2}{*}{$\begin{array}{l}\text { 项目 } \\
\text { Item }\end{array}$} & \multicolumn{2}{|c|}{$\begin{array}{c}\text { 株高 } \\
\text { PH (cm) }\end{array}$} & \multicolumn{2}{|c|}{$\begin{array}{c}\text { 穗长 } \\
\text { SL }(\mathrm{cm}) \\
\end{array}$} & \multicolumn{2}{|c|}{$\begin{array}{c}\text { 分薛数 } \\
\mathrm{TN}\end{array}$} & \multicolumn{2}{|c|}{$\begin{array}{c}\text { 单株粒数 } \\
\text { GNPP }\end{array}$} & \multicolumn{2}{|c|}{$\begin{array}{l}\text { 单株粒重 } \\
\text { GWPP (g) }\end{array}$} & \multicolumn{2}{|c|}{$\begin{array}{l}\text { 穗粒数 } \\
\text { KNPS }\end{array}$} & \multicolumn{2}{|c|}{$\begin{array}{c}\text { 千粒重 } \\
\text { TGW (g) }\end{array}$} & \multicolumn{2}{|c|}{$\begin{array}{c}\text { 产量 } \\
\mathrm{Y}\left(\mathrm{kg} \mathrm{hm}^{-2}\right) \\
\end{array}$} \\
\hline & $\mathrm{CK}$ & $\mathrm{T}$ & $\mathrm{CK}$ & $\mathrm{T}$ & $\mathrm{CK}$ & $\mathrm{T}$ & $\mathrm{CK}$ & $\mathrm{T}$ & $\mathrm{CK}$ & $\mathrm{T}$ & CK & $\mathrm{T}$ & $\mathrm{CK}$ & $\mathrm{T}$ & $\mathrm{CK}$ & $\mathrm{T}$ \\
\hline $\begin{array}{c}\text { 平均值 } \\
\text { Ave. }\end{array}$ & 79.41 & 58.59 & 7.61 & 6.31 & 2.66 & 2.29 & 62.77 & 52.11 & 3.01 & 2.31 & 23.67 & 21.04 & 48.84 & 43.42 & 3.07 & 1.45 \\
\hline $\begin{array}{c}\text { 变异系数 } \\
\mathrm{CV}\end{array}$ & 0.086 & 0.105 & 0.084 & 0.136 & 0.078 & 0.150 & 0.101 & 0.128 & 0.146 & 0.185 & 0.098 & 0.121 & 0.070 & 0.074 & 0.083 & 0.412 \\
\hline $\begin{array}{c}\text { 标准误 } \\
\text { SE }\end{array}$ & \multicolumn{2}{|c|}{6.623} & \multicolumn{2}{|c|}{0.666} & \multicolumn{2}{|c|}{0.261} & \multicolumn{2}{|c|}{7.352} & \multicolumn{2}{|c|}{0.325} & \multicolumn{2}{|c|}{1.808} & \multicolumn{2}{|c|}{3.077} & \multicolumn{2}{|c|}{2.428} \\
\hline $\begin{array}{c}t \text { 值 } \\
t \text {-value }\end{array}$ & \multicolumn{2}{|c|}{17.218} & \multicolumn{2}{|c|}{10.746} & \multicolumn{2}{|c|}{7.794} & \multicolumn{2}{|c|}{7.946} & \multicolumn{2}{|c|}{10.919} & \multicolumn{2}{|c|}{7.985} & \multicolumn{2}{|c|}{9.655} & \multicolumn{2}{|c|}{5.855} \\
\hline $\begin{array}{c}P \text { 值 } \\
P \text {-value }\end{array}$ & \multicolumn{2}{|c|}{$0.0001^{* *}$} & \multicolumn{2}{|c|}{$0.0001^{* *}$} & \multicolumn{2}{|c|}{$0.0001^{* *}$} & \multicolumn{2}{|c|}{$0.0001^{* *}$} & \multicolumn{2}{|c|}{$0.0001^{* *}$} & \multicolumn{2}{|c|}{$0.0001^{* *}$} & \multicolumn{2}{|c|}{$0.0001^{* *}$} & \multicolumn{2}{|c|}{$0.0001^{* *}$} \\
\hline $\begin{array}{c}\text { 相关系数 } \\
r\end{array}$ & \multicolumn{2}{|c|}{0.499} & \multicolumn{2}{|c|}{0.652} & \multicolumn{2}{|c|}{0.665} & \multicolumn{2}{|c|}{0.382} & 0.6 & 81 & 0.7 & & 0.58 & & & 52 \\
\hline
\end{tabular}

数据为 2016 和 2017 两年的平均值。 $\mathrm{CK}$ : 正常供水处理; $\mathrm{T}$ : 干旱胁迫处理。 ${ }^{* *}$ 表示在 $P<0.01$ 水平差异显著。

PH: plant height; SL: spike length; TN: tiller number; GNPP: grain number per plant; GWPP: grain weight per plant; GNS: grain number per spike; TGW: 1000-grain weight; Y: yield. Data are the mean across 2016 and 2017. CK: normal water supply treatments; T: drought treatments. ${ }^{* *}$ : significantly different at $P<0.01$.

表 3 供试大麦种质各指标的抗旱系数

Table 3 Drought resistance coefficients of all indexes in tested barley germplasm

\begin{tabular}{|c|c|c|c|c|c|c|c|c|}
\hline 编号 & 株高 & 穗长 & 分菅数 & 单株粒数 & 单株粒重 & 穗粒数 & 千粒重 & 产量 \\
\hline Number & $\mathrm{PH}$ & EL & $\mathrm{TN}$ & GNPP & GWPP & KNPS & TGW & $\mathrm{Y}$ \\
\hline 01 & 0.845 & 0.889 & 0.962 & 0.968 & 0.850 & 0.936 & 0.875 & 0.815 \\
\hline 02 & 0.683 & 0.901 & 0.867 & 0.772 & 0.884 & 0.775 & 0.934 & 0.462 \\
\hline 03 & 0.815 & 0.917 & 0.981 & 0.937 & 0.862 & 0.925 & 0.902 & 0.823 \\
\hline 04 & 0.662 & 0.853 & 0.913 & 0.825 & 0.905 & 0.785 & 0.990 & 0.370 \\
\hline 05 & 0.774 & 0.909 & 0.926 & 0.878 & 0.810 & 0.887 & 0.936 & 0.384 \\
\hline 06 & 0.707 & 0.794 & 0.759 & 0.783 & 0.704 & 0.723 & 0.806 & 0.369 \\
\hline 07 & 0.778 & 0.815 & 0.767 & 0.759 & 0.736 & 0.793 & 0.824 & 0.393 \\
\hline 08 & 0.722 & 0.797 & 0.750 & 0.790 & 0.690 & 0.820 & 0.830 & 0.403 \\
\hline 09 & 0.763 & 0.875 & 0.857 & 0.824 & 0.815 & 0.891 & 0.955 & 0.442 \\
\hline 10 & 0.752 & 0.964 & 0.926 & 0.867 & 0.757 & 0.939 & 0.884 & 0.728 \\
\hline 11 & 0.709 & 0.840 & 0.988 & 0.885 & 0.905 & 0.974 & 0.841 & 0.442 \\
\hline 12 & 0.837 & 0.779 & 0.739 & 0.966 & 0.913 & 0.944 & 0.982 & 0.744 \\
\hline 13 & 0.879 & 0.904 & 0.964 & 0.960 & 0.859 & 0.956 & 0.910 & 0.806 \\
\hline 14 & 0.736 & 0.921 & 0.929 & 0.898 & 0.814 & 0.976 & 0.807 & 0.424 \\
\hline 15 & 0.640 & 0.766 & 0.852 & 0.789 & 0.798 & 0.828 & 0.822 & 0.361 \\
\hline 16 & 0.715 & 0.725 & 0.690 & 0.753 & 0.596 & 0.721 & 0.815 & 0.293 \\
\hline 17 & 0.722 & 0.821 & 0.788 & 0.924 & 0.794 & 0.897 & 0.856 & 0.377 \\
\hline 18 & 0.749 & 0.970 & 0.929 & 0.792 & 0.854 & 0.954 & 0.990 & 0.493 \\
\hline 19 & 0.566 & 0.766 & 0.962 & 0.781 & 0.679 & 0.973 & 0.944 & 0.499 \\
\hline 20 & 0.813 & 0.749 & 0.907 & 0.792 & 0.750 & 0.871 & 0.871 & 0.503 \\
\hline 21 & 0.637 & 0.789 & 0.875 & 0.715 & 0.741 & 0.881 & 0.935 & 0.466 \\
\hline 22 & 0.788 & 0.759 & 0.739 & 0.749 & 0.663 & 0.882 & 0.904 & 0.329 \\
\hline
\end{tabular}


(续表 3)

\begin{tabular}{|c|c|c|c|c|c|c|c|c|}
\hline 编号 & 株高 & 穗长 & 分䔉数 & 单株粒数 & 单株粒重 & 穗粒数 & 千粒重 & 产量 \\
\hline Number & $\mathrm{PH}$ & EL & $\mathrm{TN}$ & GNPP & GWPP & KNPS & TGW & $\mathrm{Y}$ \\
\hline 23 & 0.750 & 0.654 & 0.706 & 0.591 & 0.671 & 0.828 & 0.906 & 0.231 \\
\hline 24 & 0.773 & 0.757 & 0.857 & 0.775 & 0.701 & 0.942 & 0.954 & 0.329 \\
\hline 25 & 0.782 & 0.787 & 0.740 & 0.980 & 0.657 & 0.978 & 0.937 & 0.385 \\
\hline 26 & 0.687 & 0.786 & 0.963 & 0.865 & 0.808 & 0.949 & 0.867 & 0.441 \\
\hline 27 & 0.834 & 0.944 & 0.966 & 0.982 & 0.985 & 0.953 & 0.953 & 0.839 \\
\hline 28 & 0.683 & 0.782 & 0.815 & 0.889 & 0.707 & 0.902 & 0.855 & 0.274 \\
\hline 29 & 0.718 & 0.991 & 0.964 & 0.929 & 0.670 & 0.938 & 0.839 & 0.385 \\
\hline 30 & 0.670 & 0.636 & 0.687 & 0.588 & 0.475 & 0.853 & 0.794 & 0.273 \\
\hline 平均值 Ave. & 0.740 & 0.828 & 0.859 & 0.834 & 0.768 & 0.889 & 0.891 & 0.469 \\
\hline 变异系数 CV & 0.093 & 0.106 & 0.113 & 0.122 & 0.140 & 0.083 & 0.066 & 0.373 \\
\hline
\end{tabular}

PH: plant height; SL: spike length; TN: tiller number; GNPP: grain number per plant; GWPP: grain weight per plant; GNS: grain number per spike; TGW: 1000-grain weight; Y: yield.

表 4 供试大麦种质各指标抗旱系数在不同区间的分布

Table 4 Distribution in DC intervals for drought resistance coefficients of all indexes in tested barley germplasm

\begin{tabular}{|c|c|c|c|c|c|c|c|c|c|c|}
\hline \multirow{2}{*}{$\begin{array}{l}\text { 指标 } \\
\text { Index }\end{array}$} & \multicolumn{2}{|c|}{$0<\mathrm{DC}<0.2$} & \multicolumn{2}{|c|}{$0.2<\mathrm{DC}<0.4$} & \multicolumn{2}{|c|}{$0.4<\mathrm{DC}<0.6$} & \multicolumn{2}{|c|}{$0.6<\mathrm{DC}<0.8$} & \multicolumn{2}{|c|}{$0.8<\mathrm{DC}<1.0$} \\
\hline & $\begin{array}{l}\text { 次数 } \\
\text { Times }\end{array}$ & $\begin{array}{c}\text { 频率 } \\
\text { Freq.(\%) }\end{array}$ & $\begin{array}{l}\text { 次数 } \\
\text { Times }\end{array}$ & $\begin{array}{c}\text { 频率 } \\
\text { Freq.(\%) }\end{array}$ & $\begin{array}{l}\text { 次数 } \\
\text { Times }\end{array}$ & $\begin{array}{c}\text { 频率 } \\
\text { Freq.(\%) }\end{array}$ & $\begin{array}{l}\text { 次数 } \\
\text { Times }\end{array}$ & $\begin{array}{c}\text { 频率 } \\
\text { Freq.(\%) }\end{array}$ & $\begin{array}{l}\text { 次数 } \\
\text { Times }\end{array}$ & $\begin{array}{c}\text { 频率 } \\
\text { Freq.(\%) }\end{array}$ \\
\hline 株高 PH & 0 & 0 & 0 & 0 & 1 & 3 & 23 & 77 & 6 & 20 \\
\hline 穗长 EL & 0 & 0 & 0 & 0 & 0 & 0 & 14 & 47 & 16 & 53 \\
\hline 分藮数 TN & 0 & 0 & 0 & 0 & 0 & 0 & 10 & 33 & 20 & 67 \\
\hline 单株粒数 GNPP & 0 & 0 & 0 & 0 & 2 & 6.7 & 12 & 40 & 16 & 53.3 \\
\hline 单株粒 GWPP & 0 & 0 & 0 & 0 & 1 & 3 & 15 & 50 & 14 & 47 \\
\hline 穗粒数 KNPS & 0 & 0 & 0 & 0 & 0 & 0 & 5 & 17 & 25 & 83 \\
\hline 千粒重 TGW & 0 & 0 & 0 & 0 & 0 & 0 & 1 & 3 & 29 & 97 \\
\hline 产量 Y & 0 & 0 & 14 & 46.7 & 10 & 33.3 & 2 & 6.7 & 4 & 13.3 \\
\hline
\end{tabular}

Freq.: frequency; PH: plant height; SL: spike length; TN: tiller number; GNPP: grain number per plant; GWPP: grain weight per plant; GNS: grain number per spike; TGW: 1000-grain weight; Y: yield.

相关分析表明(表 5), 各指标均至少与一个 分藮数、单株粒数、单株粒重呈极显著正相关, 其它指标呈显著或极显著相关，说明各指标间与穗粒数呈显著正相关、与千粒重呈不显著正 存在一定程度的相关性。其中产量与株高、穗长、相关。

表 5 供试大麦种质各指标抗旱系数的相关性

Table 5 Correlation coefficients among drought resistance coefficients of all indexes in tested barley germplasm

\begin{tabular}{|c|c|c|c|c|c|c|c|c|}
\hline $\begin{array}{l}\text { 指标 } \\
\text { Index }\end{array}$ & $\begin{array}{c}\text { 株高 } \\
\mathrm{PH} \\
\end{array}$ & $\begin{array}{c}\text { 穗长 } \\
\mathrm{EL} \\
\end{array}$ & $\begin{array}{c}\text { 分䕌数 } \\
\mathrm{TN}\end{array}$ & $\begin{array}{c}\text { 单株粒数 } \\
\text { GNPP }\end{array}$ & $\begin{array}{c}\text { 单株粒重 } \\
\text { GWPP }\end{array}$ & $\begin{array}{l}\text { 穗粒数 } \\
\text { KNPS }\end{array}$ & $\begin{array}{c}\text { 千粒重 } \\
\text { TGW }\end{array}$ & $\begin{array}{c}\text { 产量 } \\
\mathrm{Y}\end{array}$ \\
\hline 株高 PH & - & & & & & & & \\
\hline 穗长 EL & 0.298 & - & & & & & & \\
\hline 分菣数 $\mathrm{TN}$ & 0.069 & $0.705^{* *}$ & - & & & & & \\
\hline 单株粒数 GNPP & $0.478^{* *}$ & $0.641^{* *}$ & $0.507^{* *}$ & - & & & & \\
\hline 单株粒重 GWPP & $0.339^{*}$ & $0.620^{* *}$ & $0.622^{* *}$ & $0.599^{* *}$ & 一 & & & \\
\hline 穗粒数 KNPS & 0.270 & $0.370^{*}$ & $0.558^{* *}$ & $0.562^{* *}$ & 0.288 & - & & \\
\hline 千粒重 TGW & 0.194 & 0.250 & 0.254 & 0.187 & $0.471^{* *}$ & 0.313 & - & \\
\hline 产量 Y & $0.571^{* *}$ & $0.555^{* *}$ & $0.553^{* *}$ & $0.626^{* *}$ & $0.629^{* *}$ & $0.451^{*}$ & 0.319 & - \\
\hline
\end{tabular}

*和**分别表示在 $P<0.05$ 和 $P<0.01$ 水平显著相关。

* and ${ }^{* *}$ are significant correlation at $P<0.05$ and $P<0.01$, respectively. PH: plant height; SL: spike length; TN: tiller number; GNPP: grain number per plant; GWPP: grain weight per plant; GNS: grain number per spike; TGW: 1000-grain weight; Y: yield. 


\section{3 主成分分析}

由表 6 可见，各因子特征值中前 5 个因子的 累积贡献率达 $86.39 \%$, 其特征根 $>0.697$ 。因此, 提取前 5 个因子, 将具有同等效果的指标归为一 类，可将原来各指标换成 5 个新的互相独立的综
合指标(分别以 $F_{1} 、 F_{2} 、 F_{3} 、 F_{4}$ 和 $F_{5}$ 表示)。 $F_{1}$ 在 分菜数上有较高载荷, $F_{2}$ 在产量上有较高载荷, $F_{3}$ 在穗粒数和株高上有较高载荷, $\mathrm{F}_{4}$ 在单株粒重和 千粒重上有较高载荷, $\mathrm{F}_{5}$ 在穗长和单株粒数上有 较高载荷。

表 6 供试大麦种质各指标主成分的特征向量及贡献率

Table 6 Eigenvectors and contribution rates of principal components of all indexes in tested barley germlasm

\begin{tabular}{|c|c|c|c|c|c|}
\hline \multirow{2}{*}{$\begin{array}{l}\text { 指标 } \\
\text { Index }\end{array}$} & \multicolumn{5}{|c|}{ 因子载荷 Factor loading } \\
\hline & $\mathrm{F}_{1}$ & $\mathrm{~F}_{2}$ & $\mathrm{~F}_{3}$ & $\mathrm{~F}_{4}$ & $\mathrm{~F}_{5}$ \\
\hline 株高 PH & 0.423 & -0.631 & 0.728 & -0.076 & 0.240 \\
\hline 穗长 EL & -1.420 & 0.407 & -0.032 & 0.026 & -0.731 \\
\hline 分藍数 $\mathrm{TN}$ & 0.580 & -0.020 & -0.234 & -0.424 & -0.120 \\
\hline 单株粒数 GNPP & 0.214 & -0.252 & 0.272 & -0.284 & 0.661 \\
\hline 单株粒重 GWPP & 0.259 & 0.049 & -0.513 & 0.917 & 0.324 \\
\hline 穗粒数 KNPS & -0.246 & -0.055 & 0.821 & 0.192 & -0.097 \\
\hline 千粒重 TGW & -0.205 & -0.049 & 0.153 & 0.555 & -0.066 \\
\hline 产量 Y & -0.202 & 0.662 & -0.116 & -0.190 & 1.392 \\
\hline 特征根 Characteristic root & 3.107 & 1.267 & 0.963 & 0.802 & 0.697 \\
\hline 贡献率 Contribution rate (\%) & 39.46 & 15.68 & 11.96 & 9.94 & 8.38 \\
\hline 累计贡献率 Cumulative contribution (\%) & 39.46 & 55.27 & 65.33 & 77.21 & 86.39 \\
\hline 因子权重 Factor weight & 0.453 & 0.189 & 0.135 & 0.109 & 0.103 \\
\hline
\end{tabular}

PH: plant height; SL: spike length; TN: tiller number; GNPP: grain number per plant; GWPP: grain weight per plant; GNS: grain number per spike; TGW: 1000-grain weight; Y: yield.

\section{4 供试大麦种质资源的综合抗旱性评价}

供试大麦种质资源的 CDC 值和 WDC 值分别介 于 $0.622 \sim 0.932$ 和 $0.610 \sim 0.930$, 平均值分别为 0.758 和 0.777 , 变异系数分别为 0.085 和 0.088 , 根据 CDC 值和 WDC 值的大小对 30 份供试大麦种质资源进行 抗旱性排序，其结果基本保持一致(表 7)。其中，抗 旱性强的材料有甘啤 7 号、NEVAND、MERIT、西 藏 25 和 Z06-278-9, 抗旱性弱的材料为 Aspen、中黄
1 号和 0420-7, 其余种质资源介于两者之间。此外, 供试的 30 份大麦种质资源的 $D$ 值介于 $0.106 \sim 0.931$ 之间, 平均值为 0.512 , 变异系数为 0.361 , 同时根据 $D$ 值的大小对供试大麦种质资源排序, 得到抗旱性 强的材料为甘啤 7 号、NEVAND、Z06-278-9、MERIT 和西藏 25, 抗旱性弱的材料有 Aspen、中黄 1 号和 0420-7，其余种质材料介于两者之间(表 7), 这与基 于 CDC 和 WDC 值的抗旱性鉴定结果高度吻合。

表 7 供试大麦种质抗旱性评价的 CDC 值、WDC 值和 $D$ 值

Table 7 CDC-value, WDC-value, and $D$-value of drought resistance evaluation in tested barley resources

\begin{tabular}{|c|c|c|c|c|c|c|c|c|c|c|c|}
\hline \multirow{2}{*}{$\begin{array}{c}\text { 编号 } \\
\text { Number }\end{array}$} & \multicolumn{5}{|c|}{ 隶属函数 Subordinate function value } & \multirow{2}{*}{$\begin{array}{c}\mathrm{CDC} \text { 值 } \\
\text { CDC-value }\end{array}$} & \multirow{2}{*}{$\begin{array}{l}\text { 排序 } \\
\text { Rank }\end{array}$} & \multirow{2}{*}{$\begin{array}{c}D \text { 值 } \\
D \text {-value }\end{array}$} & \multirow{2}{*}{$\begin{array}{l}\text { 排序 } \\
\text { Rank }\end{array}$} & \multirow{2}{*}{$\begin{array}{c}\text { WDC 值 } \\
\text { WDC-value }\end{array}$} & \multirow{2}{*}{$\begin{array}{l}\text { 排序 } \\
\text { Rank }\end{array}$} \\
\hline & $\mu_{1}$ & $\mu_{2}$ & $\mu_{3}$ & $\mu_{4}$ & $\mu_{5}$ & & & & & & \\
\hline 01 & 0.879 & 0.741 & 0.893 & 0.852 & 0.891 & 0.893 & 4 & 0.852 & 3 & 0.891 & 4 \\
\hline 02 & 0.534 & 0.270 & 0.776 & 0.094 & 0.745 & 0.785 & 15 & 0.481 & 17 & 0.778 & 15 \\
\hline 03 & 0.888 & 0.632 & 0.487 & 0.859 & 0.536 & 0.895 & 3 & 0.837 & 4 & 0.894 & 3 \\
\hline 04 & 0.536 & 0.142 & 0.641 & 0.737 & 0.804 & 0.788 & 14 & 0.457 & 18 & 0.779 & 14 \\
\hline 05 & 0.606 & 0.343 & 0.630 & 0.378 & 0.805 & 0.813 & 10 & 0.554 & 10 & 0.804 & 10 \\
\hline 06 & 0.289 & 0.538 & 0.535 & 0.860 & 0.625 & 0.706 & 27 & 0.338 & 27 & 0.699 & 27 \\
\hline 07 & 0.363 & 0.633 & 0.575 & 0.288 & 0.379 & 0.733 & 23 & 0.417 & 20 & 0.726 & 23 \\
\hline 08 & 0.342 & 0.573 & 0.653 & 0.165 & 0.796 & 0.725 & 26 & 0.388 & 22 & 0.718 & 25 \\
\hline 09 & 0.571 & 0.443 & 0.647 & 0.769 & 0.806 & 0.803 & 11 & 0.545 & 11 & 0.794 & 12 \\
\hline
\end{tabular}


(续表 7)

\begin{tabular}{|c|c|c|c|c|c|c|c|c|c|c|c|}
\hline \multirow{2}{*}{$\begin{array}{c}\text { 编号 } \\
\text { Number }\end{array}$} & \multicolumn{5}{|c|}{ 隶属函数 Subordinate function value } & \multirow{2}{*}{$\begin{array}{c}\text { CDC 值 } \\
\text { CDC-value }\end{array}$} & \multirow{2}{*}{$\begin{array}{l}\text { 排序 } \\
\text { Rank }\end{array}$} & \multirow{2}{*}{$\begin{array}{c}D \text { 值 } \\
D \text {-value }\end{array}$} & \multirow{2}{*}{$\begin{array}{l}\text { 排序 } \\
\text { Rank }\end{array}$} & \multirow{2}{*}{$\begin{array}{c}\text { WDC 值 } \\
\text { WDC-value }\end{array}$} & \multirow{2}{*}{$\begin{array}{l}\text { 排序 } \\
\text { Rank }\end{array}$} \\
\hline & $\mu_{1}$ & $\mu_{2}$ & $\mu_{3}$ & $\mu_{4}$ & $\mu_{5}$ & & & & & & \\
\hline 10 & 0.751 & 0.485 & 0.478 & 0.553 & 0.858 & 0.852 & 6 & 0.698 & 6 & 0.848 & 6 \\
\hline 11 & 0.660 & 0.177 & 0.563 & 0.497 & 0.327 & 0.823 & 8 & 0.564 & 8 & 0.815 & 8 \\
\hline 12 & 0.764 & 1.000 & 0.404 & 0.553 & 0.615 & 0.863 & 5 & 0.811 & 5 & 0.859 & 5 \\
\hline 13 & 0.908 & 0.775 & 0.512 & 0.423 & 0.549 & 0.905 & 2 & 0.882 & 2 & 0.902 & 2 \\
\hline 14 & 0.628 & 0.280 & 0.550 & 0.473 & 0.771 & 0.813 & 9 & 0.559 & 9 & 0.805 & 9 \\
\hline 15 & 0.375 & 0.239 & 1.000 & 0.530 & 0.735 & 0.732 & 24 & 0.348 & 26 & 0.724 & 24 \\
\hline 16 & 0.143 & 0.646 & 0.754 & 0.833 & 0.463 & 0.664 & 29 & 0.243 & 28 & 0.655 & 28 \\
\hline 17 & 0.491 & 0.491 & 0.654 & 0.222 & 0.902 & 0.772 & 18 & 0.491 & 16 & 0.764 & 18 \\
\hline 18 & 0.692 & 0.257 & 0.397 & 0.056 & 0.816 & 0.841 & 7 & 0.605 & 7 & 0.832 & 7 \\
\hline 19 & 0.486 & 0.000 & 0.579 & 0.562 & 0.540 & 0.771 & 19 & 0.389 & 21 & 0.761 & 19 \\
\hline 20 & 0.510 & 0.609 & 0.907 & 0.838 & 0.757 & 0.782 & 13 & 0.529 & 13 & 0.775 & 16 \\
\hline 21 & 0.430 & 0.213 & 0.536 & 0.437 & 0.666 & 0.755 & 21 & 0.387 & 23 & 0.746 & 21 \\
\hline 22 & 0.318 & 0.657 & 0.507 & 0.467 & 1.000 & 0.727 & 25 & 0.386 & 24 & 0.715 & 22 \\
\hline 23 & 0.123 & 0.579 & 0.591 & 1.000 & 0.649 & 0.667 & 28 & 0.214 & 29 & 0.654 & 29 \\
\hline 24 & 0.422 & 0.452 & 0.880 & 0.554 & 0.545 & 0.761 & 20 & 0.428 & 19 & 0.749 & 20 \\
\hline 25 & 0.492 & 0.716 & 0.509 & 0.000 & 0.310 & 0.781 & 12 & 0.537 & 12 & 0.770 & 17 \\
\hline 26 & 0.568 & 0.212 & 0.364 & 0.571 & 0.781 & 0.796 & 13 & 0.497 & 15 & 0.787 & 13 \\
\hline 27 & 1.000 & 0.657 & 0.566 & 0.515 & 0.848 & 0.932 & 1 & 0.931 & 1 & 0.930 & 1 \\
\hline 28 & 0.379 & 0.341 & 0.781 & 0.528 & 0.615 & 0.738 & 22 & 0.372 & 25 & 0.728 & 22 \\
\hline 29 & 0.597 & 0.183 & 0.540 & 0.725 & 0.675 & 0.804 & 11 & 0.514 & 14 & 0.796 & 11 \\
\hline 30 & 0.000 & 0.531 & 0.077 & 0.496 & 0.417 & 0.622 & 30 & 0.106 & 30 & 0.610 & 30 \\
\hline 平均值 Average & - & - & - & - & - & 0.785 & - & 0.512 & - & 0.777 & - \\
\hline 变异系数 CV & - & - & - & - & - & 0.085 & - & 0.361 & - & 0.088 & - \\
\hline
\end{tabular}

$\mu_{1}$ 和 $\mu_{2}$ 分别表示 2 个因子的隶属函数值。

$\mu_{1}$ and $\mu_{2}$ are subordinate function values of two factors, respectively.

\section{5 灰色关联度分析}

由表 8 可以看出, 各指标 DC 值与 $D$ 值间的关 联度大小依次为产量、单株粒重、单株粒数、穗长、 株高、分藮、穗粒数和千粒重，反映了各指标 DC 值
与 $D$ 值的密切程度, 这与各指标对干旱胁迫反应的 敏感性基本吻合。另外，各指标 DC 值与 WDC 值间 的关联度大小依次为单株粒重、产量、单株粒数、 分葟数、穗长、穗粒数、株高和千粒重。

\section{表 8 供试大麦种质各指标 DC 值与 $D$ 值和 WDC 值的关联度及各指标权重}

Table 8 Correlation degree between DC-value of all indexes and $D$-value together with WDC-value and indexes weight in tested barley germplasm

\begin{tabular}{lccccc}
\hline \multicolumn{1}{c}{ 指标 } & $\begin{array}{c}\text { 关联度 } \\
\text { Index }\end{array}$ & $\begin{array}{c}\text { 排序 } \\
\text { Rank }\end{array}$ & $\begin{array}{c}\text { 权重系数 } \\
\text { Weight }\end{array}$ & $\begin{array}{c}\text { 关联度 } \\
\text { Correlation degree }\end{array}$ \\
\hline 株高 PH & 0.71289 & 5 & 0.124 & 0.64220 \\
Rank
\end{tabular}

缩写同表 6 。 Abbreviations are the same as those given in Table 6. 


\section{6 聚类分析及抗旱级别的划分}

在 $\lambda=5$ 处将 30 份大麦种质资源分为 5 类(图 1)。 其中, 第 1 类为高度抗旱材料, 包括甘啤 7 号、 Z06-278-9、MERIT、西藏 25 和 NEVADA 共 5 份, 占 总数的 $16.7 \%$; 此外，根据供试种质材料的综合抗 旱性评价结果, 这 5 份种质材料的 CDC 值、WDC 值、 $D$ 值在所有参试种质资源中始终位于前 5 。第 2 类为抗旱材料, 1 份占总数的 $3.3 \%$; 第 3 类为中等抗 旱材料共 10 份, 占总数的 $33.3 \%$; 第 4 类为敏感材 料共 11 份，占总数的 $36.7 \%$; 第 5 类为高度敏感型 材料共 3 份，占总数的 $10.0 \%$ 。

根据供试种质资源的抗旱性聚类分析及抗旱 级别划分结果, 对供试种质资源抗旱性评价指标 进行分级统计, 结果表明(表 9)除了分菜数和千粒 重外, 其余指标的隶属函数值、 CDC 值、 $D$ 值和 WDC 值均随着抗旱级别的升高而增大。此外, CDC 值、 $D$ 值和 WDC 值在不同抗旱级别上的差 异较大, 可以为其他大麦种质资源抗旱级别的划 分提供依据。

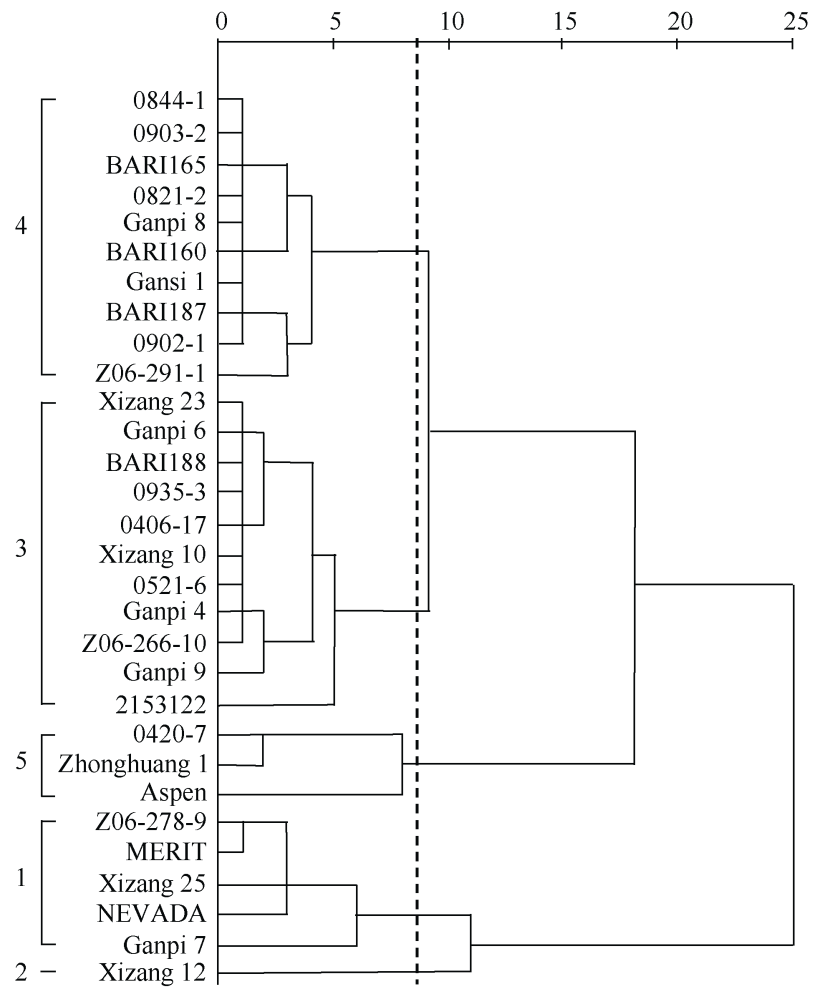

图 1 基于 $D$ 值的供试大麦材料抗旱性系统聚类图

Fig. 1 Fuzzy clustering dendrogram of drought resistance in tested barley materials on $D$-value

$1 、 2 、 3 、 4 、 5$ 表示不同抗旱级别。

$1,2,3,4$, and 5 represent different drought resistance levels.

\section{7 抗旱指标的篮选}

分别以 D 值、CDC 值和 WDC 值为参考序列，对 供试种质资源各指标 DC 值进行回归分析, 得到的 3 个回归方程的决定系数 $R^{2} \approx 1, F$ 检验均达到极显著 水平(表 10), 说明回归方程最优, 模型拟合度好, 预 测精度高, 用这 3 个回归方程进行大麦种质资源成 株期抗旱性评价的效果好。根据 $D$ 值与各指标 DC 值的回归方程可知, 在大麦种质资源成株期抗旱性 评价中, 有针对性地测定与 $D$ 值密切相关的指标, 如穗长、单株粒数、单株粒重、穗粒数和产量可鉴 定大麦种质资源的抗旱性，从而使鉴定工作简化。 灰色关联度分析中各指标 DC 值与 $D$ 值间的关联度 大小排序也更进一步印证了这一点, 即, 穗长、单株 粒数、单株粒重、穗粒数和产量可以有效作为大麦 成株期抗旱性鉴定评价指标。此外，相关分析还表 明, 供试种质资源产量、 $D$ 值、CDC 值和 WDC 值 两两之间均呈极显著正相关。

\section{3 讨论}

\section{1 大麦成株期抗旱性评价方法的选择}

评价作物的抗旱性不仅需要选择合适的评价指 标, 而且要适宜的评价方法。将多种方法和多种指 标相结合的手段在芝麻 ${ }^{[35]}$ 、水稻 ${ }^{[36]}$ 、油菜 ${ }^{[12]}$ 、小麦 ${ }^{[37]}$ 、 菜豆 ${ }^{[38]}$ 等作物种质资源抗旱性评价工作中被普遍采 用。在以往的研究中, 大多数采用等权重的方法, 而 没有考虑各指标对干旱胁迫的反应敏感程度。本研 究采用 $D$ 值、 $\mathrm{CDC}$ 值和 WDC 值等综合评价指标, 结 合单项指标抗旱系数、相关分析、频次分析、主成 分分析、灰色关联度分析、隶属函数分析、聚类分 析以及回归分析，对大麦种质资源的抗旱性进行综 合评价, 消除各指标单位不同带来的影响; 同时, 结合指标变异系数来确定各指标在抗旱评价中的重 要程度, 对抗旱密切相关的指标赋予较高的权重。 本研究中将参试大麦种质资源的 $D$ 值、 CDC 值和 WDC 值排序, 其结果基本一致。相关分析表明, 供试材 料的产量、 $D$ 值、 $\mathrm{CDC}$ 值和 WDC 值之间均呈极显著 正相关，基于 $D$ 值的供试种质资源抗旱系统聚类分析 结果与各种质资源田间实际抗旱性表现更为接近, 且 产量与 $D$ 之相关最密切。因此，以 $D$ 值为评价指标的 评价方法, 既考虑了各指标的重要性, 又考虑了各指标 之间的相互关系，评价结果客观可靠。 
表 9 供试大麦种质抗旱性评价指标的分级

Table 9 Classification of drought resistance evaluation indexes in tested barley germplasm

\begin{tabular}{|c|c|c|c|c|c|}
\hline \multirow{2}{*}{$\begin{array}{l}\text { 指标 } \\
\text { Index }\end{array}$} & \multicolumn{5}{|c|}{ 隶属函数 Subordinate function value } \\
\hline & 1 & 2 & 3 & 4 & 5 \\
\hline 株高 PH & 0.883 & 0.593 & 0.555 & 0.415 & 0.466 \\
\hline 穗长 EL & 0.923 & 0.705 & 0.653 & 0.427 & 0.100 \\
\hline 分藍数 $\mathrm{TN}$ & 0.781 & 0.793 & 0.695 & 0.471 & 0.024 \\
\hline 单株粒数 GNPP & 0.951 & 0.709 & 0.707 & 0.501 & 0.141 \\
\hline 单株粒重 GWPP & 0.821 & 0.630 & 0.552 & 0.504 & 0.208 \\
\hline 穗粒数 KNPS & 0.865 & 0.848 & 0.764 & 0.513 & 0.310 \\
\hline 千粒重 TGW & 0.664 & 0.457 & 0.509 & 0.471 & 0.226 \\
\hline 产量 Y & 0.945 & 0.818 & 0.328 & 0.243 & 0.057 \\
\hline CDC 值 CDC-value & 0.898 & 0.852 & 0.801 & 0.744 & 0.651 \\
\hline$D$ 值 $D$-value & 0.863 & 0.698 & 0.534 & 0.391 & 0.188 \\
\hline WDC 值 WDC-value & 0.895 & 0.848 & 0.793 & 0.734 & 0.640 \\
\hline
\end{tabular}

$1 、 2 、 3 、 4 、 5$ 表示不同抗旱级别。缩写同表 6 。

$1,2,3,4$, and 5 represent different degree of drought resistance. Abbreviations are the same as those given in Table 6.

表 10 供试大麦种质抗旱性模型预测

Table 10 Model predict of drought resistance in tested barley germplasm

\begin{tabular}{|c|c|c|c|c|c|c|c|}
\hline \multirow[b]{2}{*}{$\begin{array}{c}\text { 因变量 } \\
\text { Dependent variable }\end{array}$} & \multirow[b]{2}{*}{$\begin{array}{c}\text { 回归方程 } \\
\text { Regression equation }\end{array}$} & \multirow[b]{2}{*}{$\begin{array}{l}\text { 决定系 } \\
\text { 数 } R^{2}\end{array}$} & \multirow[b]{2}{*}{$\begin{array}{c}F \text { 值 } \\
F \text {-value }\end{array}$} & \multirow[b]{2}{*}{$\begin{array}{c}P \text { 值 } \\
P \text {-value }\end{array}$} & \multicolumn{3}{|c|}{ 相关系数 $r$} \\
\hline & & & & & $\begin{array}{c}\text { CDC 值 } \\
\text { CDC- } \\
\text { value }\end{array}$ & $\begin{array}{c}\text { WDC 值 } \\
\text { WDC- } \\
\text { value }\end{array}$ & $\begin{array}{c}\text { 产量 } \\
\mathrm{Y}\end{array}$ \\
\hline CDC 值 CDC-value & $y=0.144+0.179 x_{2}+0.095 x_{4}+0.193 x_{5}+0.215 x_{6}+0.157 x_{8}$ & 0.985 & 314.79 & $<0.001$ & $0.885^{* *}$ & $0.999^{* *}$ & $0.869^{* *}$ \\
\hline$D$ 值 $D$-value & $y=-0.888+0.290 x_{2}+0.514 x_{4}+0.560 x_{5}+0.455 x_{6}-0.194 x_{8}$ & 0.991 & 517.65 & $<0.001$ & & $0.900^{* *}$ & $0.562^{* *}$ \\
\hline $\begin{array}{l}\text { WDC 值 } \\
\text { WDC-value }\end{array}$ & $y=0.122+0.191 x_{2}+0.104 x_{4}+0.207 x_{5}+0.224 x_{6}+0.139 x_{8}$ & 0.987 & 362.79 & $<0.001$ & & & $0.854^{* *}$ \\
\hline
\end{tabular}

$x_{2}$ : 穗长; $x_{4}$ : 单株粒数; $x_{5}$ : 单株粒重; $x_{6}$ ：穗粒数; $x_{8}$ : 产量。“"表示在 $P<0.01$ 水平差异显著。

$x_{2}$ : spike length; $x_{4}$ : grain number per plant; $x_{5}$ : grain weight per plant; $x_{6}$ : grain number per spike; $x_{8}$ : yield. ${ }^{* *}$ : significantly different at $P<$ 0.01 .

\section{2 大麦成株期抗旱指标的篮选}

作物的抗旱性是复杂的数量性状, 是多种机制 和众多因素共同作用的结果。因此，选择合理的篮 选指标是作物抗旱鉴定的关键。目前, 国内外学者 在作物抗旱鉴定方面开展了大量研究工作，并针对 不同的作物篮选出了不同的抗旱指标 ${ }^{[36-38]}$ 。然而, 关于大麦抗旱鉴定的研究主要是从大麦萌发期和苗 期进行了形态指标、生理指标、生长发育指标、生 化指标和超微结构形态指标等多角度鉴定、指标篮 选及种质资源分级评价, 但对大麦成株期抗旱鉴定 评价及指标篮选鲜有报道。本研究选取与大麦种质 资源成株期抗旱相关的 8 个关键指标, 将其结合起 来, 采用不同方法分析, 结果显示各指标受干旱胁 迫影响的程度有所不同, 且各指标间存在一定程度 的相关性。因此, 直接利用这些指标很难客观、准 确地评价各种质资源的抗旱性, 从而影响抗旱鉴定
结果。通过主成分分析，将原来 8 个单项指标转换 成 5 个新的相互独立的综合指标, 使评价工作简化。 灰色关联度分析表明各指标与 $D$ 值的密切程度依次 为产量、单株粒重、单株粒数、穗长、株高、分竪 数、穗粒数和千粒重, 这与各指标对干旱胁迫反应 的敏感性及各指标与 WDC 值的密切程度基本吻合, 从而增加了评价工作的准确性和全面性。回归分析 表明 8 个指标均与 $D$ 值密切相关, 产量与株高、穗 长、分蒒数、单株粒数、单株粒重呈极显著正相关。 因此，在大麦种质资源成株期抗旱鉴定中，有针对 性地测定与 $D$ 值相关密切的指标, 如株高、穗长、 分葟数、单株粒数和单株粒重, 可有效鉴定大麦资 源的抗旱性, 从而使鉴定工作简化。

\section{4 结论}

干旱胁迫对大麦种质资源成株期各指标均有极 
显著影响。确定了 $D$ 值为适宜的抗旱鉴定指标。篮 选出成株期抗旱性强的大麦材料甘啤 7 号、 Z06-278-9、MERIT、NEVADA 和西藏 25。产量、 单株粒重、单株粒数、穗长均可作为大麦种质资源 成株期简单、直观的抗旱性评价指标。

\section{References}

[1] Ellis R P, Forster B P, Robinson D. Wild barley: a source of genes for crop improvement in the 21st century. $J$ Exp Bot, 2000, 51: 9-17.

[2] George T S, Brown L K, Ramsay L. Understanding the genetic control and physiological traits associated with rhizosheath production by barley (Hordeum vulgare). New Phytol, 2014, 203: 195-205.

[3] 成福云. 干旱灾害对二十一世纪初我国农业发展的影响探讨. 水利发展研究, 2002, 2(10): 31-33.

Cheng F Y. Discuss on drought disaster for influence on the agricultural development of our country at 21 st century. Water Resour Develop Res, 2002, 2(10): 31-33 (in Chinese with English abstract).

[4] 张木清, 陈如凯. 作物抗旱分子生理与遗传改良. 北京: 科学 出版社, 2005. pp 22-23.

Zhang M Q, Chen R K. Molecular Physiological and Genetic Improvement of Crop Drought Tolerance. Beijing: Science Press, 2005. pp 22-23 (in Chinese).

[5] 孟庆立, 关周博, 冯佰利, 柴岩, 胡银岗. 谷子抗旱相关性状 的主成分与模糊聚类分析．中国农业科学，2009，42: 2667-2675.

Meng Q L, Guan Z B, Feng B L, Chai Y, Hu Y G. Principal component analysis and fuzzy clustering on drought-tolerance related traits of foxtail millet. Sci Agric Sin, 2009, 42: 2667-2675 (in Chinese with English abstract).

[6] 秦岭, 杨延兵, 管延安, 张华文, 王海莲, 刘宾, 陈二影. 不同 生态区主要育成谷子品种芽期耐旱性鉴定. 植物遗传资源学 报, 2013, 14: 146-151.

Qin L, Yang Y B, Guan Y A, Zhang H W, Wang H L, Liu B, Chen E Y. Identification of drought tolerance at germination period of foxtail millet cultivars developed from different ecological regions. J Plant Genet Resour, 2013, 14: 146-151 (in Chinese with English abstract).

[7] 祁旭升, 王兴荣, 许军, 张建平, 米君. 胡麻种质资源成株期 抗旱性鉴定. 中国农业科学, 2010, 43: 3076-3087.

Qi X S, Wang X R, Xu J, Zhang J P, Mi J. Drought-resistance evaluation of flax germplasm at adult plant stage. Sci Agric Sin, 2010, 43: 3076-3087 (in Chinese with English abstract).

[8] 张彦军, 苟作旺, 王兴荣, 陈伟英, 祁旭升. 胡麻种质萌发期 抗旱性综合评价. 植物遗传资源学报, 2015, 16: 520-527.

Zhang Y J, Gou Z W, Wang X R, Chen W Y, Qi X S. Comprehensive valuation of drought resistance of flax germplasm in germination. J Plant Genet Resour, 2015, 16: 520-527 (in Chinese with English abstract).

[9] 罗俊杰, 欧巧明, 叶春雷, 王方, 王镛臻, 陈玉梁. 重要胡麻 栽培品种的抗旱性综合评价及指标篮选. 作物学报, 2014, 40: 1259-1273.
Luo J J, Ou Q M, Ye C L, Wang F, Wang Y Z, Chen Y L. Comprehensive valuation of drought resistance and screening of indexes of important flax cultivars. Acta Agron Sin, 2014, 40: 1259-1273 (in Chinese with English abstract).

[10] 王利彬, 刘丽君, 裴宇峰, 董守坤, 孙聪姝, 祖伟, 阮英慧. 大 豆种质资源芽期抗旱性鉴定. 东北农业大学学报, 2012, 43(1): 36-42.

Wang L B, Liu L J, Pei Y F, Dong S K, Sun C S, Zu W, Ruan Y H. Drought resistance identification of soybean germplasm resources at bud stage. J Northeast Agricl Univ, 2012, 43(1): $36-42$.

[11] 祁旭升, 刘章雄, 关荣霞, 王兴荣, 苟作旺, 常汝镇, 邱丽娟. 大豆成株期抗旱性鉴定评价方法研究. 作物学报, 2012, 38: 665-674.

Qi X S, Liu Z X, Guan R X, Wang X R, Gou Z W, Chang R Z, Qiu L J. Comparison of evaluation methods for drought-resistance at soybean adult stage. Acta Agron Sin, 2012, 38: 665-674 (in Chinese with English abstract).

[12] 朱宗河, 郑文寅, 张学坤. 甘蓝型油菜耐旱相关性状的主成分 分析. 中国农业科学, 2011, 44: 1775-1787.

Zhu Z H, Zheng W Y, Zhang X K. Principal component analysis and comprehensive evaluation on morphological and agronomic traits of drought tolerance in rapeseed. Sci Agric Sin, 2011, 44: 1775-1787 (in Chinese with English abstract).

[13] 谢小玉, 张霞, 张兵. 油菜苗期抗旱性评价及抗旱相关指标变 化分析. 中国农业科学, 2013, 46: 476-485.

Xie X Y, Zhang X, Zhang B. Evaluation of drought resistance and analysis of variation of relevant parameters at seedling stage of rapeseed. Sci Agric Sin, 2013, 46: 476-485 (in Chinese with English abstract).

[14] 陈玉梁, 石有太, 罗俊杰, 王蒂, 厚毅清, 李忠旺, 张秉贤. 甘 肃彩色棉抗旱性农艺性状指标的篮选鉴定. 作物学报, 2012, 38: 1680-1687.

Chen Y L, Shi Y T, Luo J J, Wang D, Hou Y Q, Li Z W, Zhang B $X$. Screening of drought tolerant agronomic trait indexes of colored cotton varieties (lines) in Gansu province Acta Agron Sin, 2012, 38: 1680-1687 (in Chinese with English abstract).

[15] 王艺陶, 周宇飞, 李丰先, 依兵, 白薇, 问粀, 许文娟, 高明超, 黄瑞冬. 基于主成分和 SOM 聚类分析的高粱品种萌发期抗 旱性鉴定与分类. 作物学报, 2014, 40: 110-121.

Wang Y T, Zhou Y F, Li F X, Yi B, Bai W, Yan T, Xu W J, Gao M C, Huang R D. Identification and classification of sorghum cultivars for drought resistance during germination stage based on principal components analysis and self organizing map cluster analysis. Acta Agron Sin, 2014, 40: 110-121 (in Chinese with English abstract).

[16] 吴奇, 周宇飞, 高悦, 张娇, 陈冰汝, 许文娟, 黄瑞冬. 不同高 粱品种萌发期抗旱性篮选与鉴定. 作物学报, 2016, 42: 1233-1246.

Wu Q, Zhou Y F, Gao Y, Zhang J, Chen B R, Xu W J, Huang R D. Screening and identification for drought resistance during germination in sorghum cultivars. Acta Agron Sin, 2016, 42: 1233-1246 (in Chinese with English abstract).

[17] 汪灿, 周棱波, 张国兵, 徐燕, 张立异, 高旭, 高杰, 姜讷, 邵 明波. 酒用糯高粱资源成株期抗旱性鉴定及抗旱指标篮选. 中国农业科学, 2017, 50: 1388-1402. 
Wang C, Zhou L B, Zhang G B, Xu Y, Zhang L Y, Gao X, Gao J, Jiang N, Shao M B. Drought resistance identification and drought resistance indexes screening of liquor-making waxy sorghum resources at adult plant stage. Sci Agric Sin, 2017, 50: 1388-1402 (in Chinese with English abstract).

[18] 王兰芬, 武晶, 景惢莲, 程须珍, 王述民. 绿豆种质资源芽期 抗旱性鉴定. 植物遗传资源学报, 2014, 15: 498-503.

Wang L F, Wu J, Jing R L, Cheng X Z, Wang S M. Drought resistance identification of mungbean germplasm resources at bud stage. J Plant Genet Resour, 2014, 15: 498-503 (in Chinese with English abstract).

[19] 王兰芬, 武晶, 景惢莲, 程须珍, 王述民. 绿豆种质资源苗期 抗旱性鉴定. 作物学报, 2015, 41: 145-153.

Wang L F, Wu J, Jing R L, Cheng X Z, Wang S M. Drought resistance identification of mungbean germplasm resources at seedling stage. Acta Agron Sin, 2015, 41:145-153 (in Chinese with English abstract).

[20] 王兰芬, 武晶, 景惢莲, 程须珍, 王述民. 绿豆种质资源成株 期抗旱性鉴定. 作物学报, 2015, 41: 1287-1294.

Wang L F, Wu J, Jing R L, Cheng X Z, Wang S M. Identification of mungbean germplasm resources resistance to drought at adult stage. Acta Agron Sin, 2015, 41: 1287-1294 (in Chinese with English abstract).

[21] 汪灿, 周棱波, 张国兵, 张立异, 徐燕, 高旭, 姜讷, 邵明波. 薏药种质资源苗期抗旱性鉴定及抗旱指标篮选. 中国农业科 学, 2017, 50: 2872-2887.

Wang C, Zhou L B, Zhang G B, Zhang L Y, Xu Y, Gao X, Jiang N, Shao M B. Drought resistance identification and drought resistance indexes screening of Job's Tears (Coxi lacryma-jobi L.) germplasm resources at seedling stage. Sci Agric Sin, 2017, 50: 2872-2887 (in Chinese with English abstract).

[22] 汪灿, 周棱波, 张国兵, 张立异, 徐燕, 高旭, 姜讷, 邵明波. 薏药种质资源成株期抗旱性鉴定及抗旱指标篮选. 作物学报, 2017, 43: 1381-1394.

Wang C, Zhou L B, Zhang G B, Zhang L Y, Xu Y, Gao X, Jiang $\mathrm{N}$, Shao M B. Identification and indexes screening of drought resistance at adult plant stage in job's tears germplasm resources. Acta Agron Sin, 2017, 43: 1381-1394 (in Chinese with English abstract).

[23] 赵东宾, 张海禄, 王仙, 齐军仓, 惠宏杉, 林立昊, 王凤, 郑许 光. 大麦叶片表皮蜡质组分和含量及其与抗旱性的关系. 新 疆农业科学, 2017, 54(1): 43-50.

Zhao D B, Zhang H L, Wang X, Qi J C, Hui H B, Lin L H, Wang F, Zheng X G. Relationship between epicuticular wax components and its content and drought resistance in barley leaf. Xinjiang Agric Sci, 2017, 54(1): 43-50 (in Chinese with English abstract)

[24] 张海禄, 齐军仓. 大麦叶片表皮蜡质含量与抗旱性的关系研 究. 新疆农业科学, 2012, 49(1): 22-27.

Zhang H L, Qi J C. Study on the relationship between epicuticular wax content of barley leaves and drought resistance. Xinjiang Agric Sci, 2012, 49(1): 22-27 (in Chinese with English abstract).

[25] 谢蕾蕾. 蜡质对大麦缺失突变体 MB-1-5 抗旱性影响及蜡质基 因初步定位. 甘肃农业大学硕士学位论文, 甘肃兰州, 2017.

Xie L L. Effect of Wax on Drought Resistance of Mutant MB-1-5 and Primary of Waxy Gene in Barley. MS Thesis of Gansu Agricultural University, Lanzhou, Gansu, China, 2017 (in Chinese with English abstract).

[26] 鞠乐, 齐军仓, 贺雪, 王丹, 侯忠庆, 付强, 熊显鹏. 大麦种子 萌发期对渗透胁迫的响应及抗旱性鉴定指标的篮选. 干旱地 区农业研究, 2013, 31(1): 172-176.

Ju L, Qi J C, He X, Wang D, Hou Z Q, Fu Q, Xiong X P. The response of barley to osmotic stress during germination stage and the screening of drought resistance indicators. Agric Res Arid Areas, 2013, 31(1): 172-176 (in Chinese with English abstract).

[27] 鞠乐, 齐军仓, 成禄艳, 赵佳, 廖永兵. 大麦种子萌发期对干 旱胁迫的生理响应及其抗旱性评价. 西南农业学报, 2013, 26(1): 93-98.

Ju L, Qi J C, Cheng L Y, Zhao J, Liao Y B. Physiological response of barley to drought stress during seed germination period and drought resistance evaluation. Southwest China J Agric Sci, 2013, 26(1): 93-98 (in Chinese with English abstract).

[28] 鞠乐, 齐军仓, 贺雪, 王丹. 大麦种子萌发期抗旱性鉴定指标 的篮选及抗旱性评价. 新疆农业科学, 2016, 53: 2008-2014.

Ju L, Qi J C, He X, Wang D. Screening drought resistance identification index and drought resistance evaluation in barley during seed germination period. Xinjiang Agric Sci, 2016, 53: 2008-2014 (in Chinese with English abstract).

[29] 马小英, 贾方兴, 赵颖岗, 赵杰才. 干旱和盐胁迫中大麦实时 定量 PCR 内参基因的篮选. 分子植物育种, 2016, 11: 3093-3101.

Ma X Y, Jia F X, Zhao Y L, Zhao J C. Reference genes screening for quantitative real-time PCR in barley under drought and salt stress. Mol Plant Breed, 2016, 11: 3093-3101 (in Chinese with English abstract).

[30] 汪军成, 孟亚雄, 徐先良, 王晋, 赖勇, 李葆春, 马小乐, 王化 俊. 大麦苗期抗旱性鉴定及评价. 干旱地区农业研究, 2013, 31(4): 135-143.

Wang J C, Meng Y X, Xu X L, Wang J, Lai Y, Li B C, Ma X L, Wang H J. Identification and assessment on drought-resistance of Hordeum vulgare L. at seedling stage. Agric Res Arid Areas, 2013, 31(4): 135-143 (in Chinese with English abstract).

[31] 蒋花. 大麦生长初期的抗旱生理特性研究. 西北农林科技大 学硕士学位论文, 陕西杨凌, 2012.

Jiang H. Study on Physiologic Characteristics of Initial Growth Barley Materials Related to Drought-Resistance. MS Thesis of Northwest A\&F University, Yangling, Shaanxi, China, 2012 (in Chinese with English abstract).

[32] 惠宏斌. 干旱胁迫对大麦幼苗根系的影响及其与抗旱性关系 的研究. 石河子大学硕士学位论文, 新疆石河子, 2016.

Hui H B. Effects of Drought Stress on Barley Seedling Roots with Different Drought Resistance. MS Thesis of Shihezi University, Shihezi, Xinjiang, China, 2016 (in Chinese with English abstract).

[33] 陈健辉, 李荣, 郭培国, 夏岩石, 田长恩, 缪绅裕. 干旱胁迫 对不同耐旱性大麦品种叶片超微结构的影响. 植物学报, 2011, 46(1): 28-36.

Chen J H, Li R, Guo P G, Xia Y S, Tian C E, Miao S Y. Impact of drought stress on the ultrastructure of leaf cells in three barley genotypes differing in level of drought tolerance. Chin Bull Bot, 2011, 46(1): 28-36 (in Chinese with English abstract). 
[34] 兰巨生. 农作物综合抗旱性评价方法的研究. 西北农业学报, 1998, 7(3): 85-87.

Lan J S. Comparison of evaluating methods for agronomic drought resistance in crops. Acta Agric Boreali-Occident Sin, 1998, 7(3): 85-87 (in Chinese with English abstract).

[35] 黎冬华, 刘文萍, 张艳欣, 王林海, 危文亮, 高媛, 丁霞, 王蕾, 张秀荣. 芝麻耐旱性的鉴定方法及关联分析. 作物学报, 2013, 39: $1425-1433$.

Li D H, Liu W P, Zhang Y X, Wang L H, Wei W L, Gao Y, Ding $X$, Wang L, Zhang X R. Identification method of drought tolerance and association mapping for sesame (Sesamum indicum L.). Acta Agron Sin, 2013, 39: 1425-1433 (in Chinese with English abstract).

[36] 田又升, 谢宗铭, 吴向东, 王志军, 叶春秀, 张国丽. 水稻种 质资源萌发期抗旱性综合鉴定. 干旱地区农业研究, 2015, 33(4): 173-180.

Tian Y S, Xie Z M, Wu X D, Wang Z J, Ye C X, Zhang G L. Identification of drought tolerance of rice germplasm during germination period. Agric Res Arid Areas, 2015, 33(4): 173-180 (in Chinese with English abstract).

[37] 李国瑞, 马宏亮, 胡雯媚, 汤永禄, 荣晓椒, 㚞高琼. 西南麦 区小麦品种萌发期抗旱性综合鉴定. 麦类作物学报, 2015, 35(4): $1-9$.
Li G R, Ma H L, Hu W M, Tang Y L, Rong X J, Fan G Q. Identification of wheat cultivars for drought resistance during germination in southwest area. J Triticeae Crops, 2015, 35(4): 1-9 (in Chinese with English abstract).

[38] 李龙, 王兰芬, 武晶, 景荵莲, 王述民. 普通菜豆种质资源芽 期抗旱性鉴定. 植物遗传资源学报, 2013, 14: 600-605.

Li L, Wang L F, Wu J, Jing R L, Wang S M. Drought tolerance in common bean germplasm at bud stage. J Plant Genet Resour, 2013, 14: 600-605 (in Chinese with English abstract).

[39] 郑桂萍, 李金峰, 钱永德, 吕艳东, 刘丽华, 王伯伦. 农作物 综合抗旱性指标的评价分析. 中国农学通报, 2005, 21(10): 109-121.

Zheng G P, Li J F, Qian Y D, Lyu Y D, Liu L H, Wang B L. Evaluation on comprehensive drought resistant index of crops. Chin Agric Sci Bull, 2005, 21(10): 109-121 (in Chinese with English abstract).

[40] Kamoshita A, Babu R C, Boopathi N M, Fukai S. Phenotypic and genotypic analysis of drought-resistance traits for development of rice cultivars adapted to rainfed environments. Field Crops Res, 2008, 109: 1-23.

[41] Upadhyay H D. Variability for drought resistance related traits in the mini core collection of peanut. Crop Sci, 2005, 45: 1432-1440.

附表 1 干旱胁迫和正常灌水条件下供试大麦种质各指标测定值

Supplementary table 1 Measured values of all indices in tested Barley resources under drought stress and normal irrigation

\begin{tabular}{|c|c|c|c|c|c|c|c|c|c|c|c|c|c|c|c|c|}
\hline \multirow{2}{*}{$\begin{array}{c}\text { 编号 } \\
\text { Number }\end{array}$} & \multicolumn{2}{|c|}{$\begin{array}{c}\text { 株高 } \\
\text { PH (cm) }\end{array}$} & \multicolumn{2}{|c|}{$\begin{array}{c}\text { 穗长 } \\
\text { SL }(\mathrm{cm}) \\
\end{array}$} & \multicolumn{2}{|c|}{$\begin{array}{c}\text { 分莠数 } \\
\mathrm{TN}\end{array}$} & \multicolumn{2}{|c|}{$\begin{array}{c}\text { 单株粒数 } \\
\text { GNPP }\end{array}$} & \multicolumn{2}{|c|}{$\begin{array}{l}\text { 单株粒重 } \\
\text { GWPP (g) }\end{array}$} & \multicolumn{2}{|c|}{$\begin{array}{c}\text { 穗粒数 } \\
\text { KNPS } \\
\end{array}$} & \multicolumn{2}{|c|}{$\begin{array}{c}\text { 千粒重 } \\
\text { TGW }\end{array}$} & \multicolumn{2}{|c|}{$\begin{array}{c}\text { 产量 } \\
\mathrm{Y}\left(\mathrm{kg} \mathrm{hm}^{-2}\right)\end{array}$} \\
\hline & $\mathrm{CK}$ & $\mathrm{T}$ & CK & $\mathrm{T}$ & CK & $\mathrm{T}$ & CK & $\mathrm{T}$ & $\mathrm{CK}$ & $\mathrm{T}$ & CK & $\mathrm{T}$ & $\mathrm{CK}$ & $\mathrm{T}$ & CK & $\mathrm{T}$ \\
\hline 01 & 78.92 & 66.70 & 8.04 & 7.15 & 2.63 & 2.53 & 60.97 & 59.03 & 3.20 & 2.72 & 23.95 & 22.42 & 52.60 & 46.03 & 3.39 & 2.76 \\
\hline 02 & 89.78 & 61.33 & 7.77 & 7.00 & 2.77 & 2.40 & 69.80 & 53.90 & 3.28 & 2.90 & 26.20 & 20.30 & 47.49 & 44.36 & 2.73 & 1.26 \\
\hline 03 & 88.67 & 72.30 & 8.21 & 7.52 & 2.60 & 2.55 & 71.53 & 67.03 & 3.14 & 2.70 & 27.96 & 25.87 & 44.79 & 40.39 & 3.17 & 2.61 \\
\hline 04 & 93.49 & 61.92 & 7.92 & 6.76 & 2.67 & 2.43 & 60.93 & 50.30 & 2.88 & 2.61 & 24.95 & 19.60 & 48.40 & 47.90 & 3.32 & 1.23 \\
\hline 05 & 79.78 & 61.73 & 7.48 & 6.80 & 2.81 & 2.60 & 57.77 & 50.70 & 2.59 & 2.10 & 20.51 & 18.20 & 45.01 & 42.11 & 3.18 & 1.22 \\
\hline 06 & 83.33 & 58.94 & 6.93 & 5.50 & 2.90 & 2.20 & 58.87 & 46.10 & 2.84 & 2.00 & 21.58 & 15.60 & 48.26 & 38.92 & 3.27 & 1.21 \\
\hline 07 & 77.96 & 60.64 & 7.49 & 6.10 & 2.87 & 2.20 & 63.80 & 48.40 & 3.17 & 2.33 & 21.94 & 17.40 & 49.62 & 40.90 & 3.16 & 1.24 \\
\hline 08 & 75.82 & 54.76 & 7.90 & 6.30 & 2.80 & 2.10 & 59.23 & 46.80 & 2.90 & 2.00 & 22.21 & 18.20 & 49.06 & 40.70 & 3.05 & 1.23 \\
\hline 09 & 87.84 & 67.03 & 7.20 & 6.30 & 2.80 & 2.40 & 52.70 & 43.40 & 2.70 & 2.20 & 19.30 & 17.20 & 50.35 & 48.10 & 3.11 & 1.37 \\
\hline 10 & 86.56 & 65.06 & 7.89 & 7.61 & 2.70 & 2.50 & 66.23 & 57.40 & 3.37 & 2.55 & 24.53 & 23.03 & 50.43 & 44.56 & 3.35 & 2.44 \\
\hline 11 & 73.49 & 52.13 & 7.26 & 6.10 & 2.83 & 2.80 & 66.30 & 58.70 & 3.01 & 2.72 & 23.40 & 22.80 & 48.88 & 41.11 & 3.22 & 1.42 \\
\hline 12 & 73.83 & 61.83 & 6.80 & 5.30 & 2.30 & 1.70 & 52.20 & 50.40 & 2.30 & 2.10 & 23.40 & 22.10 & 43.90 & 43.10 & 2.73 & 2.03 \\
\hline 13 & 74.67 & 65.60 & 7.43 & 6.71 & 2.80 & 2.70 & 60.20 & 57.80 & 2.96 & 2.55 & 22.59 & 21.60 & 51.32 & 46.70 & 3.36 & 2.71 \\
\hline 14 & 74.02 & 54.44 & 7.31 & 6.73 & 2.80 & 2.60 & 65.63 & 58.97 & 3.68 & 3.00 & 23.73 & 23.16 & 56.14 & 45.31 & 2.90 & 1.23 \\
\hline 15 & 82.87 & 53.05 & 8.88 & 6.80 & 2.70 & 2.30 & 64.67 & 51.00 & 3.51 & 2.80 & 24.27 & 20.10 & 54.39 & 44.70 & 3.22 & 1.16 \\
\hline 16 & 80.50 & 57.55 & 8.00 & 5.80 & 2.90 & 2.00 & 57.40 & 43.20 & 3.35 & 2.00 & 22.60 & 16.30 & 49.30 & 40.20 & 3.31 & 0.97 \\
\hline 17 & 78.54 & 56.68 & 6.70 & 5.50 & 2.67 & 2.10 & 61.80 & 57.10 & 3.15 & 2.50 & 23.20 & 20.80 & 54.98 & 47.04 & 3.00 & 1.13 \\
\hline 18 & 69.54 & 52.05 & 6.70 & 6.50 & 2.80 & 2.60 & 62.10 & 49.20 & 3.04 & 2.60 & 22.46 & 21.42 & 49.21 & 48.72 & 2.90 & 1.43 \\
\hline 19 & 90.42 & 51.20 & 7.31 & 5.60 & 2.60 & 2.50 & 59.30 & 46.30 & 2.80 & 1.90 & 22.00 & 21.40 & 44.40 & 41.90 & 2.55 & 1.27 \\
\hline 20 & 77.14 & 62.72 & 8.41 & 6.30 & 2.50 & 2.27 & 62.87 & 49.80 & 2.80 & 2.10 & 25.70 & 22.38 & 54.40 & 47.40 & 2.62 & 1.32 \\
\hline
\end{tabular}




\begin{tabular}{|c|c|c|c|c|c|c|c|c|c|c|c|c|c|c|c|c|}
\hline \multirow{2}{*}{$\begin{array}{c}\text { 编号 } \\
\text { Number }\end{array}$} & \multicolumn{2}{|c|}{$\begin{array}{c}\text { 株高 } \\
\mathrm{PH}(\mathrm{cm})\end{array}$} & \multicolumn{2}{|c|}{$\begin{array}{c}\text { 穗长 } \\
\text { SL (cm) }\end{array}$} & \multicolumn{2}{|c|}{$\begin{array}{c}\text { 分菜数 } \\
\mathrm{TN} \\
\end{array}$} & \multicolumn{2}{|c|}{$\begin{array}{c}\text { 单株粒数 } \\
\text { GNPP }\end{array}$} & \multicolumn{2}{|c|}{$\begin{array}{l}\text { 单株粒重 } \\
\text { GWPP (g) }\end{array}$} & \multicolumn{2}{|c|}{$\begin{array}{c}\text { 穗粒数 } \\
\text { KNPS }\end{array}$} & \multicolumn{2}{|c|}{$\begin{array}{c}\text { 千粒重 } \\
\text { TGW }\end{array}$} & \multicolumn{2}{|c|}{$\begin{array}{c}\text { 产量 } \\
\mathrm{Y}\left(\mathrm{kg} \mathrm{hm}^{-2}\right) \\
\end{array}$} \\
\hline & CK & $\mathrm{T}$ & $\mathrm{CK}$ & $\mathrm{T}$ & $\mathrm{CK}$ & $\mathrm{T}$ & $\mathrm{CK}$ & $\mathrm{T}$ & $\mathrm{CK}$ & $\mathrm{T}$ & $\mathrm{CK}$ & $\mathrm{T}$ & $\mathrm{CK}$ & $\mathrm{T}$ & $\mathrm{CK}$ & $\mathrm{T}$ \\
\hline 21 & 89.86 & 57.26 & 7.60 & 6.00 & 2.40 & 2.10 & 74.27 & 53.10 & 2.70 & 2.00 & 26.23 & 23.11 & 45.64 & 42.69 & 2.59 & 1.21 \\
\hline 22 & 74.05 & 58.34 & 7.90 & 6.00 & 2.30 & 1.70 & 67.20 & 50.30 & 3.02 & 2.00 & 23.70 & 20.90 & 44.89 & 40.60 & 3.19 & 1.05 \\
\hline 23 & 74.07 & 55.54 & 6.88 & 4.50 & 2.27 & 1.60 & 84.10 & 49.70 & 4.77 & 3.20 & 31.89 & 26.40 & 51.83 & 46.93 & 2.82 & 0.65 \\
\hline 24 & 73.61 & 56.91 & 7.53 & 5.70 & 2.10 & 1.80 & 62.33 & 48.30 & 2.71 & 1.90 & 22.86 & 21.52 & 43.48 & 41.47 & 2.96 & 0.97 \\
\hline 25 & 82.25 & 64.30 & 8.90 & 7.00 & 2.43 & 1.80 & 60.10 & 58.90 & 2.74 & 1.80 & 25.25 & 24.68 & 46.37 & 43.44 & 2.75 & 1.06 \\
\hline 26 & 79.46 & 54.57 & 7.76 & 6.10 & 2.70 & 2.60 & 61.60 & 53.30 & 3.01 & 2.43 & 23.68 & 22.47 & 48.77 & 42.27 & 3.07 & 1.35 \\
\hline 27 & 80.48 & 67.10 & 8.90 & 8.40 & 2.90 & 2.80 & 66.10 & 64.90 & 2.68 & 2.64 & 23.40 & 22.30 & 51.30 & 48.90 & 3.41 & 2.86 \\
\hline 28 & 74.49 & 50.91 & 7.80 & 6.10 & 2.70 & 2.20 & 56.37 & 50.10 & 2.55 & 1.80 & 22.57 & 20.36 & 45.03 & 38.50 & 3.34 & 0.92 \\
\hline 29 & 70.80 & 50.81 & 6.86 & 6.80 & 2.80 & 2.70 & 59.90 & 55.63 & 2.84 & 1.90 & 21.77 & 20.42 & 47.44 & 39.81 & 3.03 & 1.17 \\
\hline 30 & 66.08 & 44.30 & 6.60 & 4.20 & 2.77 & 1.90 & 56.93 & 33.50 & 2.74 & 1.30 & 22.40 & 19.10 & 47.53 & 37.74 & 3.33 & 0.91 \\
\hline
\end{tabular}

数据为 2016 和 2017 两年的平均值。CK: 正常供水处理; $\mathrm{T}$ : 干旱胁迫处理。

PH: plant height; SL: spike length; TN: tiller number; GNPP: grain number per plant; GWPP: grain weight per plant; GNS: grain number per spike; TGW: 1000-grain weight; Y: yield. Data are the mean across 2016 and 2017. CK: normal water supply treatments; T: repeated drought treatment. 